\title{
First simultaneous lidar observations of sodium layers and VHF radar observations of E-region field-aligned irregularities at the low-latitude station Gadanki
}

\author{
S. Sridharan ${ }^{1}$, A. K. Patra ${ }^{1}$, N. Venkateswara Rao ${ }^{1}$, and G. Ramkumar ${ }^{2}$ \\ ${ }^{1}$ National Atmospheric Research Laboratory, Gadanki, India \\ ${ }^{2}$ Space Physics Laboratory, Vikram Sarabhai Space Centre, Trivandrum, India
}

Received: 19 May 2009 - Revised: 12 August 2009 - Accepted: 24 August 2009 - Published: 1 September 2009

\begin{abstract}
Simultaneous observations of atmospheric sodium (Na) made by a resonance lidar and E-region field-alignedirregularities (FAI) made by the Indian MST radar, both located at Gadanki $\left(13.5^{\circ} \mathrm{N}, 79.2^{\circ} \mathrm{E}\right)$ and horizontal winds acquired by a SKiYMET meteor radar at Trivandrum $\left(8.5^{\circ} \mathrm{N}\right.$, $77^{\circ} \mathrm{E}$ ) are used to investigate the relationship among sodium layer, FAI and neutral winds in the mesosphere and lower thermosphere region. The altitudes and descent rates of higher altitude $(\sim 95 \mathrm{~km}) \mathrm{Na}$ layer and FAI agree quite well. The descending structures of the higher altitude $\mathrm{Na}$ layer and FAI are found to be closely related to the diurnal tidal phase structure in zonal winds observed over Trivandrum. At lower altitudes, the descent rate of FAI is larger than that of $\mathrm{Na}$ layer and zonal tidal phase. These observations support the hypothesis that the metallic ion layers are formed by the zonal wind shear associated with tidal winds and subsequently get neutralized to manifest in the form of descending Na layers. The descending FAI echoing layers are manifestation of the instabilities setting in on the ionization layer. In the present observations, the altitudes of occurrence of $\mathrm{Na}$ layer and FAI echoes being low, we surmise that it is quite possible that the FAI echoes are due to the descent of already formed irregularities at higher altitudes.
\end{abstract}

Keywords. Ionosphere (Ion chemistry and composition; Ionospheric irregularities) - Meteorology and atmospheric dynamics (Waves and tides)

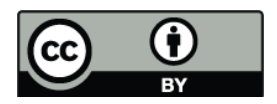

Correspondence to: S. Sridharan (ssri_dhar@rediffmail.com)

\section{Introduction}

Outside the equatorial electrojet belt, sharp electron density layers are formed by the wind shear mechanism (Whitehead, 1961). These layers are often composed of metallic ions $\left(\mathrm{Fe}^{+}, \mathrm{Na}^{+}, \mathrm{Mg}^{+}, \mathrm{Ca}^{+}\right.$etc $)$and can survive for long time due to the larger lifetime of these metallic ions as compared to that of molecular ions $\left(\mathrm{O}_{2}^{+}, \mathrm{NO}^{+}\right)$(Zhou and Morton, 2005). These layers are popularly known as sporadic E (Es) layers in the ionospheric community. These layers often turn unstable manifesting plasma irregularities and have been a topic of intense scientific investigation in the recent past (see Mathews, 1998, for a review). The diurnal and semidiurnal atmospheric tides are known to play a major role in the formation of mid-latitude sporadic E layers, acting through their vertical wind shear forcing of the long-living metallic ions in the lower thermosphere (Mathews and Bekeny, 1979; Haldoupis et al., 2006). Recent studies suggested that planetary waves play a role on Es generation as well (Haldoupis et al., 2002; Pancheva et al., 2003). Besides tides and planetary waves, gravity waves having large amplitudes and wind shears can also affect the vertical motion of plasma locally (e.g., see Chimonas, 1971).

Kane et al. (2001), using simultaneous observations of electron density by the Arecibo $\left(18.3^{\circ} \mathrm{N}, 66.8^{\circ} \mathrm{W}\right.$, dip $50^{\circ}$ ) incoherent scatter radar, Na lidar, and coherent radar backscatter from the E-region field-aligned-irregularities (FAI), made the first effort to link the plasma irregularities with the electron density and $\mathrm{Na}$ density layers. Although a clear picture on their relationship could not be established with their limited observational data, their study opened up a new dimension to study the $\mathrm{E}$ region plasma irregularities with due importance given to the coupling between the

Published by Copernicus Publications on behalf of the European Geosciences Union. 
Table 1. The MST radar specifications and other important parameters used for the FAI observations.

\begin{tabular}{ll}
\hline Parameter & Value \\
\hline Frequency & $53 \mathrm{MHz}$ \\
Transmitted peak power (maximum) & $2.5 \mathrm{MW}$ \\
Antenna & 10243 -element Yagi \\
Antenna area & $130 \times 130 \mathrm{~m}^{2}$ \\
Beam width (one-way half power) & $3^{\circ}$ \\
Beam direction & $13.2^{\circ}$ off zenith and due north \\
Receiver gain & $120 \mathrm{~dB}$ \\
Receiver bandwidth & $1.7 \mathrm{MHz}$ \\
Receiver dynamic range & $70 \mathrm{~dB}$ \\
Pulse width & $16 \mu \mathrm{s}$ \\
Interpulse period & $2000 \mu \mathrm{s}$ \\
Pulse code & Complementary code \\
Baud length & $1 \mu \mathrm{s}$ \\
Coherent integration & 4 \\
Incoherent integration & 1 \\
Number of FFT points & 128 \\
\hline
\end{tabular}

neutral and ionized particles. Earlier, Haldoupis et al. (1996) suggested that sharp horizontal conductivity gradients associated with patchy nighttime metallic ion layers could lead to strong polarization fields which would be sufficient to excite two-stream instability occurring at the mid-latitude ionosphere.

Coming to the low-latitude observations of E-region irregularities, investigations suggested that the low latitude Eregion irregularities are closely linked to the tidal and gravity wave dynamics (e.g., Patra et al., 2005, 2009; Venkateswara Rao et al., 2008). Patra et al. (2009), based on their investigation, surmised that metallic ions must be playing a crucial role in the layer formation and thus in the instability process. No experimental proof, however, could be provided so far. On the other hand, Patra et al. (2005) could not find any close link between the sporadic E layer as observed by ionosonde and the radar observed FAI. Their investigation was, however, based on limited observations, implying that much is yet to be done. Similarly, the role of thin ion layers composed of metallic ions also could not be studied due to lack of simultaneous rocket observations of such layers.

With the advent of lidar techniques to measure $\mathrm{Na}, \mathrm{Fe}$ and Ca (Bowman et al., 1969; Granier et al., 1989), it was envisaged that it would be possible to study their presence and dynamics using high temporal and vertical resolution capabilities of lidar techniques. In fact, such measurements have provided vital information on the sporadic appearance of metal layers (Gardner et al., 1993). Sporadic Na layers have been observed and are believed to be related to sporadic E, as wind shear is believed to be responsible for both sporadic $\mathrm{E}$ and subsequently the formation of sporadic Na layers by the neutralization of metal ions (Kane et al., 1993; Clemesha, 1995).

Considering the potential applications of $\mathrm{Na}$ measurements in understanding the neutral dynamics in the meso- sphere and lower thermosphere (MLT) region and the plasma irregularities in the E region, we have made a few case studies based on simultaneous observations of $\mathrm{Na}$ density and $\mathrm{E}$ region FAI made at Gadanki $\left(13.5^{\circ} \mathrm{N}, 79.2^{\circ} \mathrm{E}\right)$, a low latitude station in the southern part of India. The intent of this paper is to present the first simultaneous observations of $\mathrm{Na}$ and $\mathrm{E}$ region FAI over Gadanki and to offer an in-depth analysis using concurrent wind measurements from Trivandrum $\left(8.5^{\circ} \mathrm{N}, 77^{\circ} \mathrm{E}\right)$ using a SKiYMET meteor radar. These results are discussed in the light of current understanding on their linkage.

\section{Observations and data analysis}

\subsection{Resonance Na lidar}

The lidar system located at Gadanki has been augmented with the capability of probing $\mathrm{Na}$ atoms (Bhavani Kumar et al., 2007). The Nd:YAG laser beam of wavelength $532 \mathrm{~nm}$ is converted into $589 \mathrm{~nm}$ using a pulsed laser, which uses Kiton red as laser medium. The $589 \mathrm{~nm}$ laser beam of energy $25 \mathrm{~mJ}$ per pulse is then transmitted into the atmosphere. The receiving system consists of $750 \mathrm{~mm}$ Newtonian telescope, an interference filter and a photo multiplier tube (PMT) for photon detection. The altitude and time resolutions of the measurements are $300 \mathrm{~m}$ and $2 \mathrm{~min}$ (due to the integration of 2400 shots), respectively. Na density is derived using the equation given by Gardner (1989) as:

$n_{c}(z)=\frac{\left[N_{s}(\lambda, z)-N_{B} \Delta t\right]}{\left[N_{R}(\lambda, z)-N_{B} \Delta t\right]} \frac{z^{2}}{z_{R}^{2}} \frac{\sigma_{R} n\left(z_{R}\right)}{\sigma_{\mathrm{eff}}(\lambda)}$,

where, $n_{c}(z)$ is the concentration of $\mathrm{Na}$ atoms in the range interval $(z-\Delta z / 2, z-\Delta z / 2), z_{R}$ is the normalization altitude where molecular scattering is fairly high $(\sim 40 \mathrm{~km}), N_{s}(\lambda$, $z$ ) is the number of photons detected in the range interval $(z-\Delta z / 2, z+\Delta z / 2), N_{R}\left(\lambda, z_{R}\right)$ is the number of photons detected by the receiver arising due to Rayleigh scattering at altitude $z_{R}, N_{B}$ is the number of photons due to background noise and detector dark counts, $\sigma_{R}$ is the Rayleigh scattering cross-section, $n\left(z_{R}\right)$ is the atmospheric neutral density at altitude $z_{R}, \sigma_{R} n\left(z_{R}\right)=2.938 \times P\left(z_{R}\right) / T\left(z_{R}\right)$, where $P\left(z_{R}\right)$ and $T\left(z_{R}\right)$ are the atmospheric pressure and temperature at altitude $z_{R}$ taken from the CIRA model, and $\sigma_{\text {eff }}$ is the effective back scattering cross-section of $\mathrm{Na}$ atoms corresponding to the laser line width of $2 \mathrm{pm}(1.7 \mathrm{GHz})$, which is $5.17 \times 10^{16} \mathrm{~m}^{2}$ (Bhavani Kumar et al., 2007).

\subsection{Gadanki MST radar}

FAI observations have been made using the MST radar located at Gadanki (Rao et al., 1995). The radar operates at $53 \mathrm{MHz}$ with a maximum peak-power aperture product of $3 \times 10^{10} \mathrm{~W} \mathrm{~m}^{2}$. For FAI observations, the antenna beam is pointed at a zenith angle of $13^{\circ}$ due magnetic north, which 

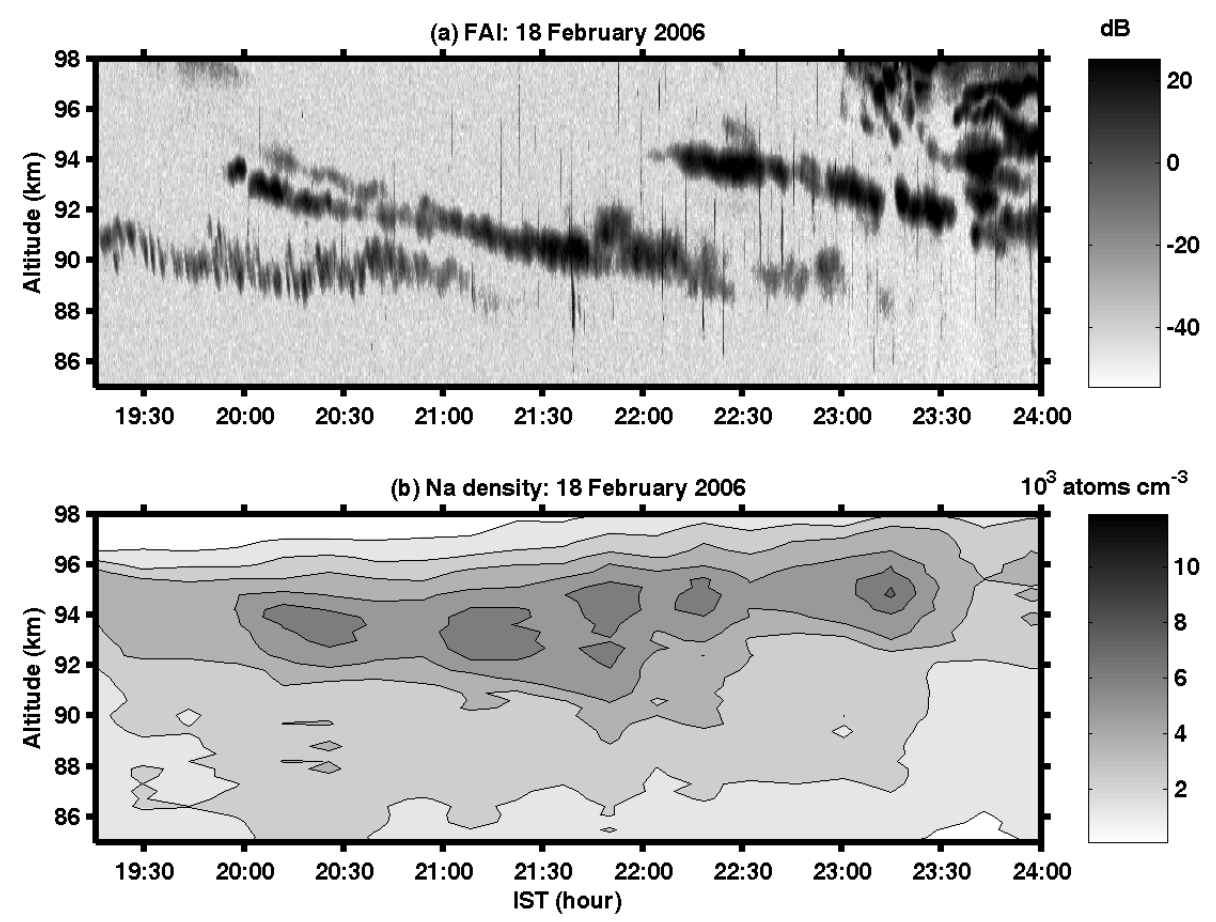

Fig. 1. Altitude-time cross section of intensity of echoes from FAI (top panel) and sodium density (bottom panel) for 18 February 2006.

is perpendicular to the earth's magnetic field. As the MST radar beam is pointed at $13^{\circ}$ zenith angle due magnetic north to get echoes from the FAI, the probing volume at $90-100 \mathrm{~km}$ is $\sim 20 \mathrm{~km}$ north of the overhead sky. Thus with respect to the lidar observed probing volume, the radar probing volume is separated by about $20 \mathrm{~km}$. The radar specifications and other important parameters used for the FAI observations are given in Table 1. With the parameters given in the table, we have obtained power spectral data from the range of 84-121.35 km with range and time resolutions of $150 \mathrm{~m}$ and $4 \mathrm{~s}$, respectively. From the power spectrum of the returned signal, three low order moments, namely, total power, weighted mean frequency shift and Doppler width have been computed. From the total power, the signal to noise ratio (SNR) is estimated. In the present work, the time altitude cross section of SNR is compared with that of $\mathrm{Na}$ density.

\subsection{SKiYMET meteor radar}

The SKiYMET meteor radar, located at Trivandrum, operates at $35.25 \mathrm{MHz}$ with a peak power of $40 \mathrm{~kW}$ (Deepa et al., 2006). A detailed description of this radar, and the meteor detection and data processing algorithm can be found in Hocking et al. (2001). The complex correlation method has been adopted to measure the phase differences between the receiving antennas in order to determine the echo arrival angle and both the complex auto and cross correlation methods to measure the rate of change of the relative phase in order to determine the radial velocity of the meteor trail. For each meteor trail, the accuracy of determination of the zenith angle of the reflection point depends on the error in the phase determination and the experimental uncertainty in zenith angle is $<3^{\circ}$. The spread in possible zenith angles for each meteor has been used in conjunction with the range to find the possible spread in heights. The average spread is $\pm 3.2 \mathrm{~km}$ due to the phase uncertainty. Thus the range error due to the pulse length $(13.33 \mu$ s pulse resulting in a range uncertainty of $2 \mathrm{~km}$ ) is also significant, giving a total uncertainty in height of about $\pm 3.8 \mathrm{~km}$ for individual meteors. As it is not productive to bin the resultant individual meteor height values into divisions finer than $\sim 3 \mathrm{~km}$, the radial velocity data are usually grouped into one hour time bins and $3 \mathrm{~km}$ height bins. The observations are grouped in altitude such that there will be sufficient number of meteor echoes to estimate meaningful winds. The instrument detects a sufficient number of meteor echoes throughout the day to obtain a comprehensive picture of the wind field. The errors in hourly mean zonal and meridional winds are dependent on meteor counts. During morning hours when hourly meteor count is roughly 100 , the errors in zonal and meridional winds are in general $\sim 0.08 \mathrm{~m} \mathrm{~s}^{-1}$ and $\sim 0.01 \mathrm{~m} \mathrm{~s}^{-1}$. During evening hours when hourly meteor count is $30-40$, the errors in zonal and meridional winds are $\sim 0.5 \mathrm{~m} \mathrm{~s}^{-1}$ and $\sim 0.2 \mathrm{~m} \mathrm{~s}^{-1}$. 

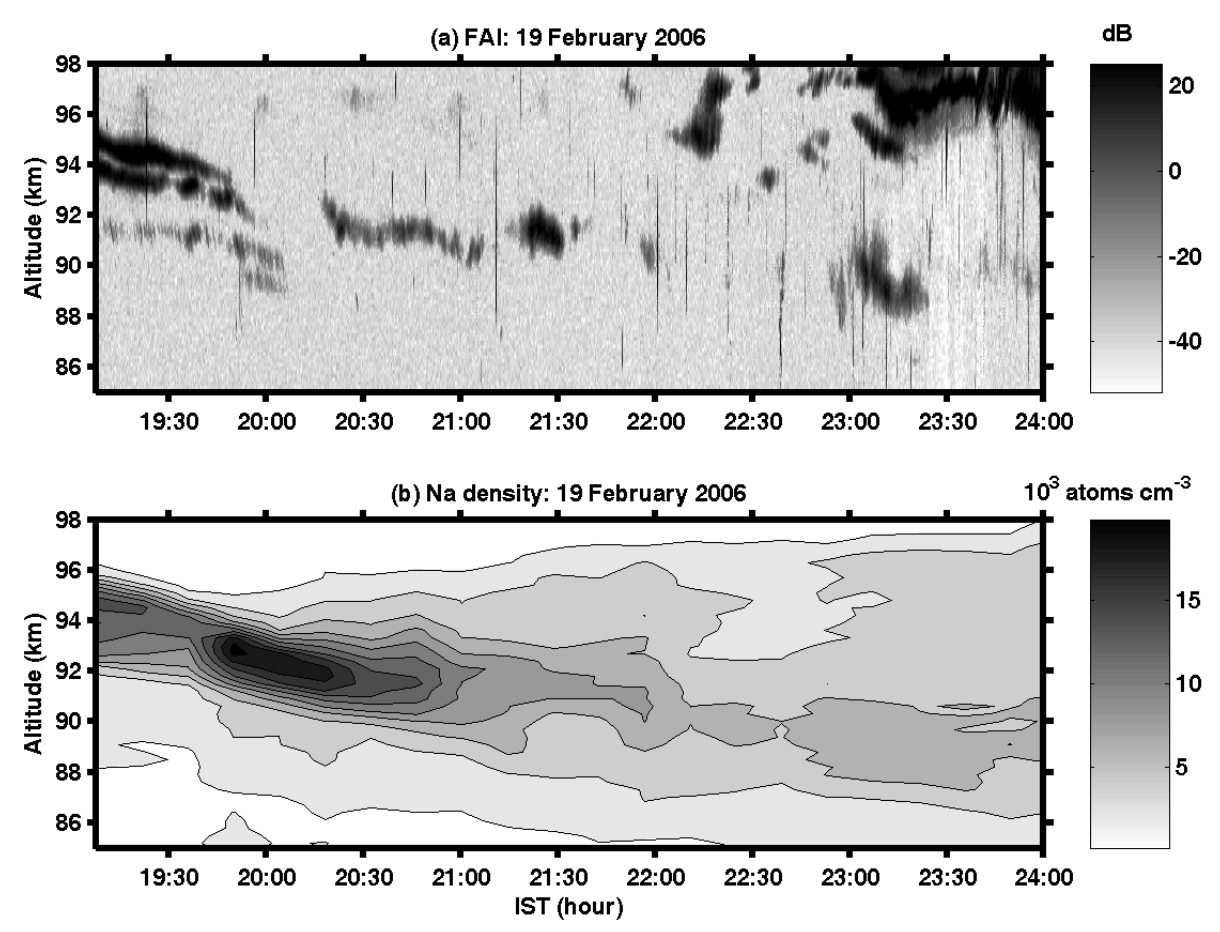

Fig. 2. Altitude-time cross section of intensity of echoes from FAI (top panel) and sodium density (bottom panel) for 19 February 2006.

\section{Results}

Figure 1 shows the altitude-time variation of SNR of the E-region FAI echoes (top panel) and Na density (bottom panel) observed during 19:00-24:00 IST (Indian Standard Time, which is five and half hours ahead of Universal Time) on 18 February 2006. The FAI echo shows successive descending structures at a time interval of $\sim 1.5 \mathrm{~h}$. These descending echoing layers are confined to $89-95 \mathrm{~km}$. It may be noticed that the second echoing layer commences only after the first echoing layer descended to $89.5 \mathrm{~km}$. Similarly, the third echoing layer commences only after the descent of the second layer to $89 \mathrm{~km}$. The descent rates of these echoing layers are $\sim 1.36 \mathrm{~km} \mathrm{~h}^{-1}, 1.6 \mathrm{~km} \mathrm{~h}^{-1}$ and $1.6 \mathrm{~km} \mathrm{~h}^{-1}$ during 18:00-19:25 IST, 21:00-21:45 IST and 22:00-23:00 IST. From the bottom panel, we can infer that the altitude regions of the peak Na density and that of FAI are found to be common. The thickness of the Na layer appears to expand with time and also enhanced density blobs are found to occur with a quasi-period of $40-60 \mathrm{~min}$. The FAI echo peak occurs at 19:45 IST, when background $\mathrm{Na}$ density is around 8000 atoms $\mathrm{cm}^{-3}$, and the $\mathrm{Na}$ density increases to over $\sim 12000$ atoms $\mathrm{cm}^{-3}$ in about $20 \mathrm{~min}$. It remains near its peak level for about $15 \mathrm{~min}$ before falling to the background level in about $15 \mathrm{~min}$. During 20:30-22:30 IST, the peaks in FAI and $\mathrm{Na}$ density occur simultaneously. However, during 23:00-23:30 IST, when the Na density increases from 9000 to 12500 atoms $\mathrm{cm}^{-3}$, the FAI echo remains below $-5 \mathrm{~dB}$. The descent rate of the Na layer $\left(0.8 \mathrm{~km} \mathrm{~h}^{-1}\right.$ dur- ing 19:00-21:30 IST), however, is much smaller than that of FAI $\left(\sim 1.4-1.6 \mathrm{~km} \mathrm{~h}^{-1}\right)$.

Figure 2 shows observations made during 19:0024:00 IST on 19 February 2006. In this case, both FAI and Na observations show descending behavior. The descent rate, however, is $1.4 \mathrm{~km} \mathrm{~h}^{-1}$ in Na density and $2 \mathrm{~km} \mathrm{~h}^{-1}$ in FAI. Notably, the Na density shows a large variation. In particular, there is a large enhancement of $\mathrm{Na}$ in the altitude region 90-95 km during the early hours of the observational period. It is noteworthy that the intensity of the FAI echoes is large prior to the enhancement of $\mathrm{Na}$ concentration. The echoes are rather diffused when Na density maximizes.

Figure 3 shows observations made during 01:0005:00 IST on 21 February 2006. There is a data gap corresponding to the first patch of FAI occurrence. However, during the last part of the FAI observations, a clear Na layer can be seen simultaneously with the FAI echo layer and time variations of both are nearly similar. Interestingly, in both the observations, a common descent rate $\left(\sim 1.5 \mathrm{~km} \mathrm{~h}^{-1}\right)$ can be noted. It may be noted that in this case, both the FAI echoes and $\mathrm{Na}$ layer are at a higher altitude (above $95 \mathrm{~km}$ ) compared to those observed on 18 February 2006 and 19 February 2006.

Using simultaneous measurements of meteor winds and the vertical distribution of atmospheric $\mathrm{Na}$, Clemesha et al. (2001) showed a clear role of tidal wind in the dynamics of the Na layer behaviour in consistence with the tides observed in the meteor winds. To examine whether the Na layer behavior has any close relationship with the neutral wind system 

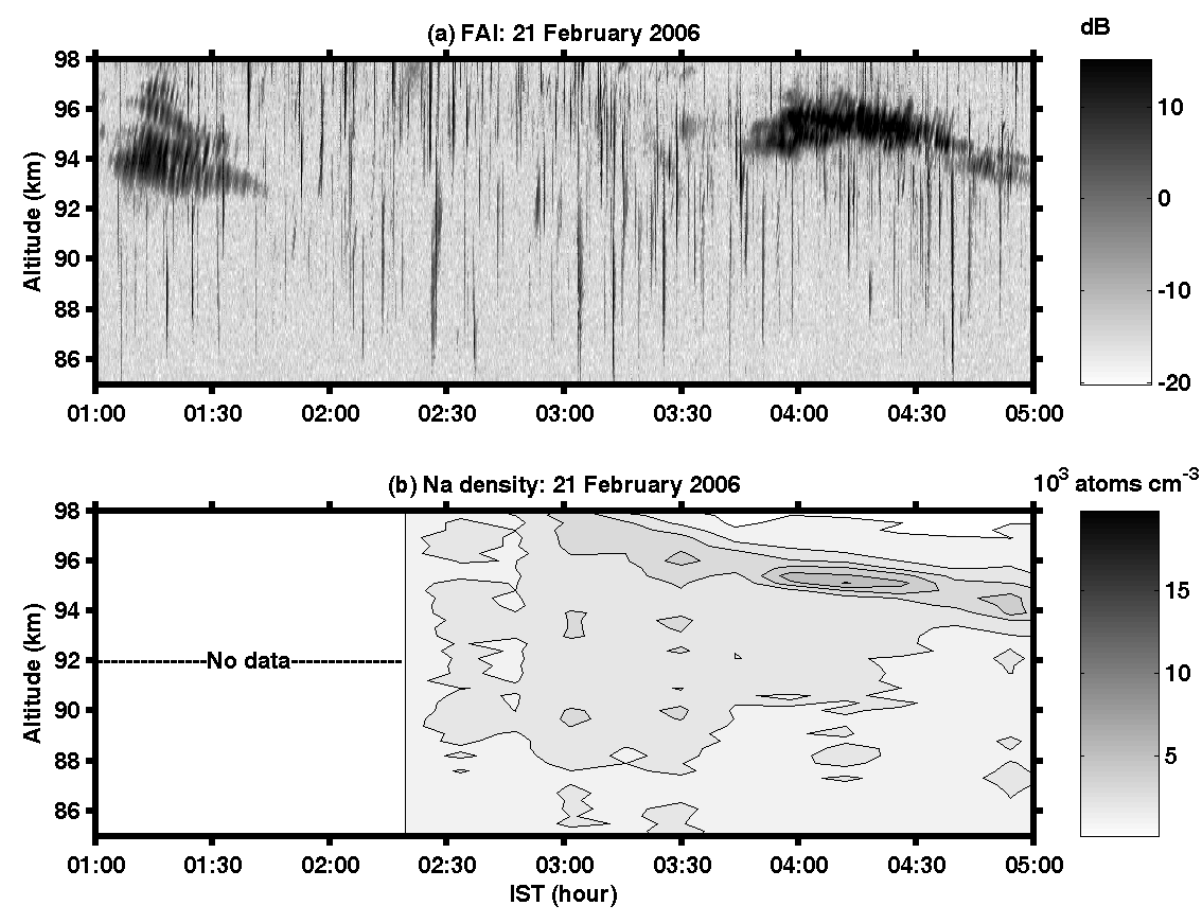

Fig. 3. Altitude-time cross section of intensity of echoes from FAI (top panel) and sodium density (bottom panel) for 21 February 2006.

and also a possible link of these with the E region FAI layers, we have analyzed the winds observed at Trivandrum. The amplitudes and phases of diurnal tides are computed using hourly values of zonal and meridional winds observed over a day at Trivandrum. The altitude profiles of diurnal tidal amplitudes and phases are shown in Fig. 4. On 18-19 February 2006 and 19-20 February 2006, the diurnal tidal amplitude in zonal wind is in the range of $20-60 \mathrm{~m} \mathrm{~s}^{-1}$ and the diurnal tidal amplitude in meridional wind is observed to be as large as $100 \mathrm{~m} \mathrm{~s}^{-1}$ or more. On 20-21 February 2006, diurnal tidal amplitude in meridional wind is as large as $\sim 70 \mathrm{~m} \mathrm{~s}^{-1}$. In all the three cases, the diurnal tidal amplitudes in zonal wind are, in general, smaller than that in meridional wind at all altitudes. The phase profiles observed in meridional winds show downward progression $\left(\sim 1 \mathrm{~km} \mathrm{~h}^{-1}\right)$ in all the three cases. On 18-19 February 2006, the zonal tidal phase descends at the rate of $0.8 \mathrm{~km} \mathrm{~h}^{-1}$, which is nearly equal to that of Na density. On 19-20 February 2006 and 20-21 February 2006 , zonal tidal phases descend at the rates of $\sim 1.2 \mathrm{~km} \mathrm{~h}^{-1}$ and $1.5 \mathrm{~km} \mathrm{~h}^{-1}$, respectively, which are similar to the descent rate $\left(1.4 \mathrm{~km} \mathrm{~h}^{-1}\right)$ observed in Na density. On 20-21 February 2006 , the zonal phase descent rate is $1.5 \mathrm{~km} \mathrm{~h}^{-1}$, which is same as the descent rates of FAI echo peak and Na layer peak. In the present observations, the zonal phase descent rate is found to be closer to the descent rate of $\mathrm{Na}$ layer peak and the descent rates of FAI echoes are relatively larger than those of $\mathrm{Na}$ density at lower altitudes (around $90 \mathrm{~km}$ ) and all three have same descent rates at higher altitudes (around $95 \mathrm{~km})$.
In order to investigate the relationship in more detail, we have analyzed observations of Na density and SNR profile of FAI along with the wind measurements made from Trivandrum. The panels in the first two rows of Fig. 5 show the observations made at 20:00 IST and 22:15 IST on 18 February 2006. At 20:00 IST, the Na density shows peak values of 8000 atoms $\mathrm{cm}^{-3}$ and 4400 atoms $\mathrm{cm}^{-3}$ at altitudes $\sim 94 \mathrm{~km}$ and $\sim 87 \mathrm{~km}$, respectively. The FAI SNR, however, peaks at $93 \mathrm{~km}$ and $90 \mathrm{~km}$ with values of $10.4 \mathrm{~dB}$ and $-3.6 \mathrm{~dB}$, respectively. At 22:15 IST, both FAI (13.6 dB) and Na density $\left(9600\right.$ atoms $\mathrm{cm}^{-3}$ ) peak nearly at same altitude of $94 \mathrm{~km}$. Note that at the base of the high altitude $\mathrm{Na}$ and FAI echo layers, there is positive wind shear (eastward wind increasing with altitude) of about $5.3 \mathrm{~m} \mathrm{~s}^{-1} \mathrm{~km}^{-1}$ and the peaks coincide with nearly zero wind shears.

Similar analysis has been done for 19 February 2006 data and the results are presented in the third and fourth rows of Fig. 5. It is apparent from the figure that the $\mathrm{Na}$ density shows a prominent peak at both 19:00 IST and 20:30 IST with a value of 15000 atoms $\mathrm{cm}^{-3}$ at $95 \mathrm{~km}$ and another less prominent peak at lower altitude just below $85 \mathrm{~km}$. The FAI SNR also shows prominent peak at $95 \mathrm{~km}$ and a less prominent one at $\sim 90 \mathrm{~km}$. It may be noted that there is a small split in the higher altitude peak of Na density at 19:00 IST and similar split can be observed in FAI echoes at 20:30 IST. The zonal wind shows a negative shear (wind decreasing with altitude) in the altitude region $88 \mathrm{~km}$ and $94 \mathrm{~km}$ with maximum of $11 \mathrm{~m} \mathrm{~s}^{-1} \mathrm{~km}^{-1}$ around $90 \mathrm{~km}$. However, peaks of FAI and $\mathrm{Na}$ density coincide with nearly zero wind shear. At 

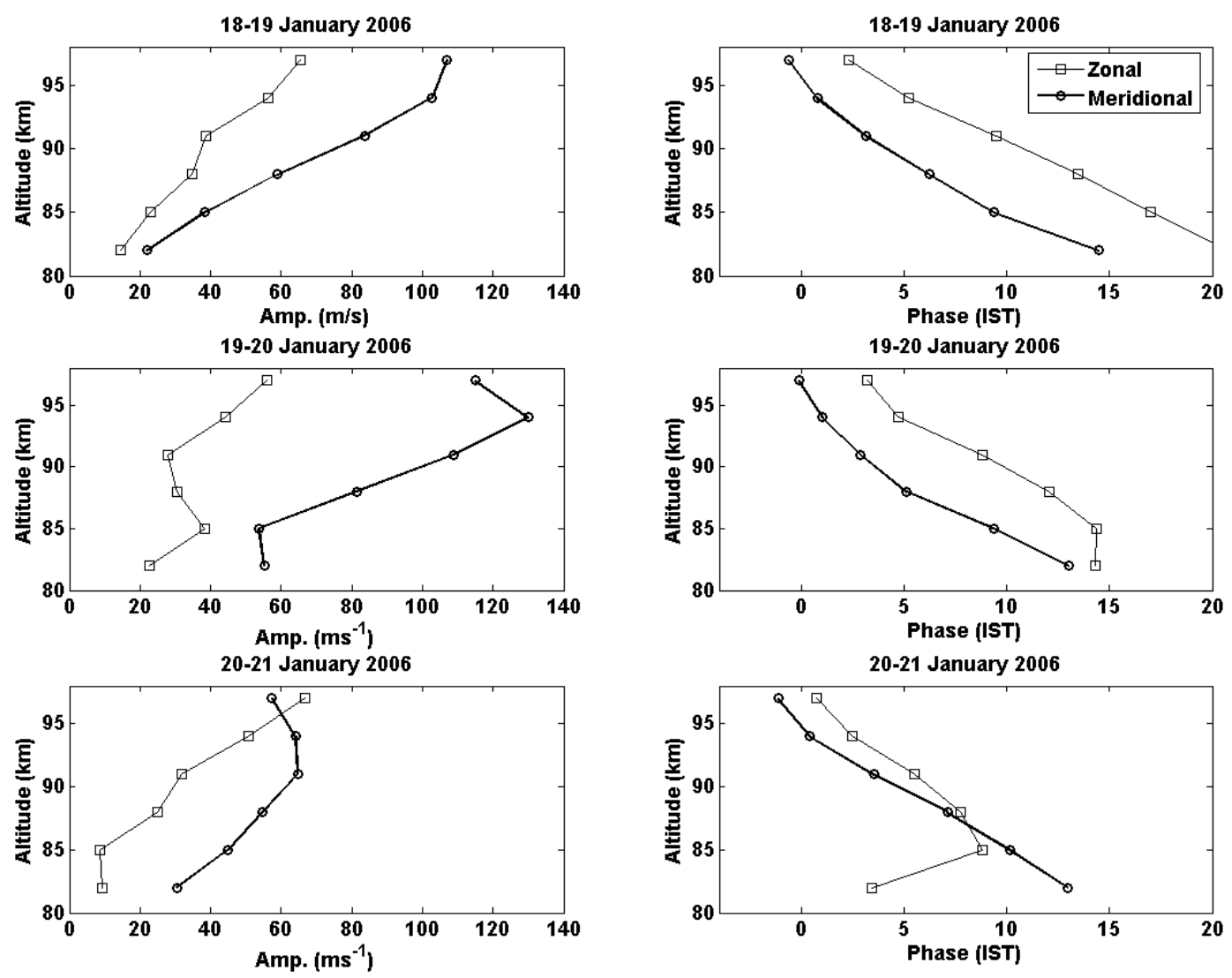

Fig. 4. Altitude profiles of amplitudes and phases of diurnal tide in meridional (curve with circles) and zonal winds (curve with squares) over Trivandrum for 19-20 February 2006 (top panels), 18-19 February 2006 (middle panels) and 20-21 February 2006 (bottom panels).

20:30 IST, Na density peak occurs at lower altitude $(92 \mathrm{~km})$, whereas FAI echo show a prominent peak at $95 \mathrm{~km}$. The FAI peak coincides with nearly zero wind shear and $\mathrm{Na}$ density peak coincides with weak negative wind shear.

On 21 February 2006, the Na layer peaks at $95 \mathrm{~km}$ with 6100 atoms $\mathrm{cm}^{-3}$ and FAI echo layer also peaks nearly at the same altitude $(95 \mathrm{~km}$ ) with a SNR of $20 \mathrm{~dB}$ (last row of Fig. 5). However, the zonal winds show eastward wind with a weak positive shear of $1 \mathrm{~m} \mathrm{~s}^{-1} \mathrm{~km}^{-1}$.

\section{Discussion and conclusion}

We have presented simultaneous observations of Na density, FAI echoes, and neutral zonal winds in the low-latitude MLT region and the results are summarized as follows: (1) Both FAI and Na density, in general, show double peaked structures with more prominent peak altitudes greater than $90 \mathrm{~km}$ and less prominent one at lower altitudes less than $90 \mathrm{~km}$. The altitude of the peak Na density and that of FAI are found to be nearly the same at higher altitudes and are not same at lower altitudes. (2) The time variations of FAI and $\mathrm{Na}$ density show sometimes similar and sometimes opposite behaviour. It may be noted that on 20 February 2006, the time variations of FAI echoes and Na density enhancement are remarkably similar and in this case, they occurred at higher altitudes (above $95 \mathrm{~km}$ ). (3) The descent rates of FAI echoes are larger than those of Na density. The zonal tidal phase descent rate is found to be close to the descent rate of Na layer. However, on 20 February 2006, the descent rates of Na layer, FAI echoes and zonal tide are nearly same with $1.5 \mathrm{~km} \mathrm{~h}^{-1}$. (4) A comparison of wind shear over Trivandrum shows that the high altitude FAI echo peak consistently coincides with nearly zero wind shear.

The descending rates of both Na concentration and FAI echoes altitude are similar and are consistent with the finding of Kane et al. (2001). The correspondence between $\mathrm{Na}$ and FAI echoes can be explained as the lidar observe sporadic $\mathrm{Na}$ associated with the Es layer (Clemesha, 1995; Friedman et al., 2000) and the FAI echo is associated with the same Es (Urbina et al., 2000). As for the Es layer formation, westward wind above and eastward wind below is most efficient in converging the ionization to form layers at the lower $\mathrm{E}$ region. In an event of descending layers formed by neutral wind (possibly of tidal origin), the observed echoing region seems to be located either close to the tidal wind node or above. Chimonas and Axford (1968) suggested that while the 

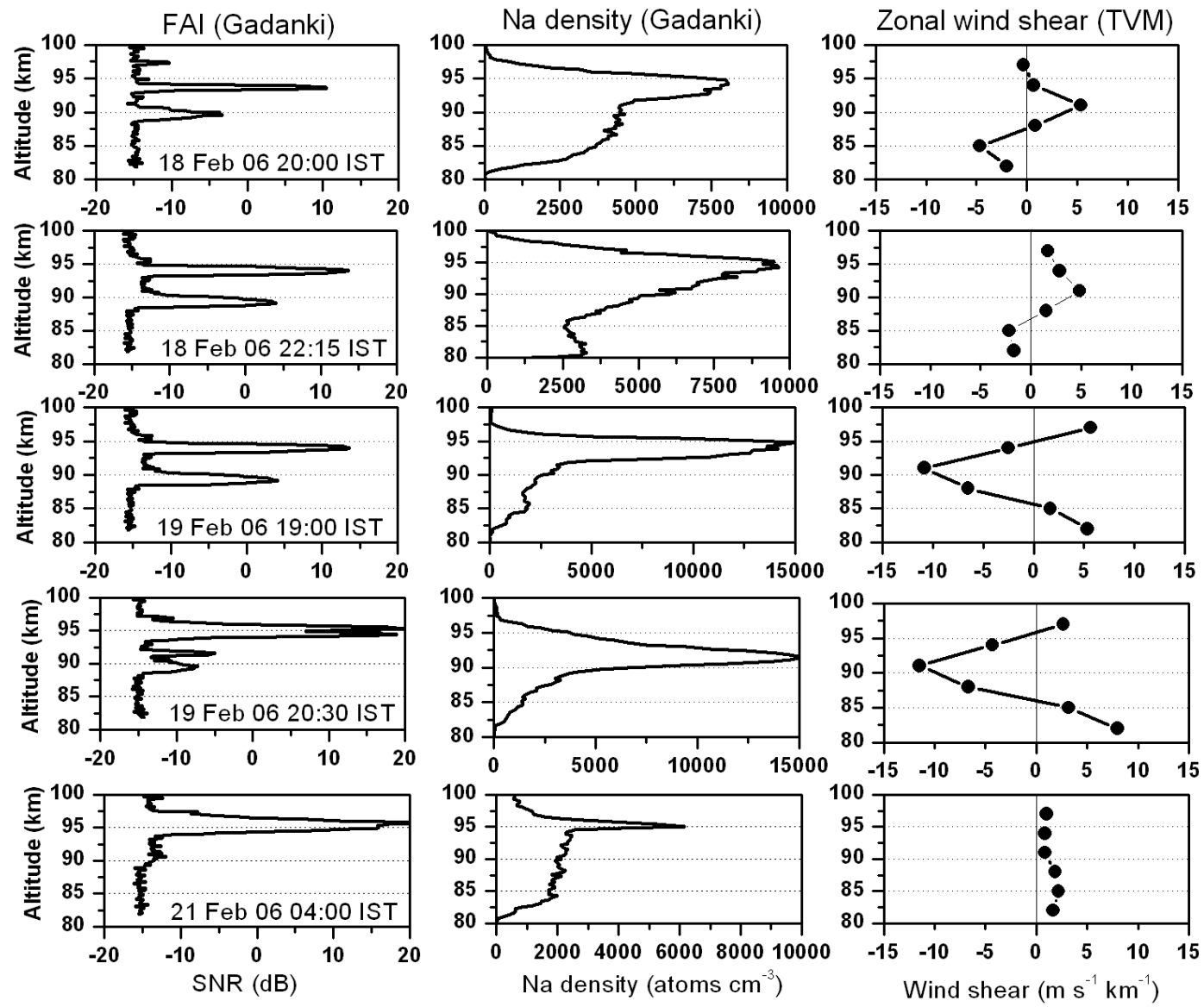

Fig. 5. Altitude profiles of echoes from FAI, Na density over Gadanki and zonal wind shear over Trivandrum at 20:00 and 22:15 IST on 18 February 2006, 19:00 and 20:30 IST on 19 February 2006 and 04:00 IST on 21 February 2006.

tidal wind node continues to descend in the collision dominated lower E region, the Es layer would be left behind since the ion-neutral collisions slow down the descent rate of the ionization layer. These sporadic E layers also contain metallic ions, which have longer life time than the molecular ions. The long-lived ions can then form layers near the nodes of the tidal wind and move with the downward directed phase velocity. At altitudes below $90 \mathrm{~km}$, ion transport is impeded and the ions are dumped in the layer region. Richter and Sechrist (1979) suggested that neutral Na atoms might then be produced from $\mathrm{Na}+$ through cluster ion reactions.

Our results show that descending structures observed in the time-altitude cross section of $\mathrm{Na}$ density are more closely related to the downward progression of diurnal tidal phase in zonal winds which is consistent with the current understanding on the formation of ionization layers (Whitehead, 1961). Clemesha et al. (2001) observed that descending structures of $\mathrm{Na}$ density were closely related to those of meridional wind profile over two closely spaced sites $\left(23^{\circ} \mathrm{S}, 45^{\circ} \mathrm{E}\right)$ in Brazilian sector.

In the present work, the westward winds and the descending structures of FAI echoes/Na density are not always coin- ciding. Of the three cases presented here, only on 19 February 2008, the zonal winds are westward when FAI echoes and $\mathrm{Na}$ density show descending layer similar to that of tidal winds. Patra et al. (2007) suggested that if the upper part of the layer (say, single peak electron density layer) providing negative electron density gradient turns unstable, then according to gradient drift instability (GDI), the differential drift of the electron and ion required for instability growth should be eastward. This is either possible through downward electric field or westward neutral wind. The GDI, which is responsible for FAI echoes, could still be produced even if the westward winds are not present, but if the downward electric field is sufficient. As an alternative, the $\mathrm{Na}$ layer formation may have taken place during daytime, when wind conditions are suitable for the formation of sporadic ionized layers.

Our results show that the altitudes of sodium enhancements and FAI echoes are not the same at lower altitudes (below $90 \mathrm{~km}$ ). The descending structures of Na density and FAI echoes are similar only at high altitudes (above $90 \mathrm{~km}$ ). Friedman et al. (2000) found that all the enhanced Na layers were having associated ion layer only above $100 \mathrm{~km}$ and 
below that altitude, some $\mathrm{Na}$ enhancements occurred without the presence of ion layers. They also observed a special event that sporadic Na layer peak occurred prior to the ion layer at the same altitude. The observations presented in the present study, however, correspond to altitudes below $100 \mathrm{~km}$. On 22 February 2006, the altitudes and descending rates of both FAI and Na density remarkably coincide with each other and with the zonal tidal phase descent rate. On this night, FAI echo and $\mathrm{Na}$ layer are observed above $95 \mathrm{~km}$. On the other two nights, though the descent rates of Na layer and FAI are nearly similar and they occur at nearly the same altitudes, the temporal variation of the structures differ in detail. This reveals that the formation of sporadic Na layer below $100 \mathrm{~km}$ is complex and needs further investigation.

It is important to mention that the simultaneous existence of large echo intensity and $\mathrm{Na}$ concentration is not expected, as the lidar observe neutral metal atoms, whereas FAI is associated with sporadic E consisting of metal ions. The FAI echoes are first observed by the radar. When the remnant metal ions are neutralized to form neutral metal layers, lidar begins to observe them. There are occasions, when FAI echo enhancement occurs prior to that in neutral $\mathrm{Na}$ density. Sometimes, the Na density and FAI echo intensity maximizes simultaneously. This suggests that not all the metal ions are neutralized to neural atoms and both metal atoms and neutral metal ions may coexist.

To understand the relationship among sporadic Na, Sporadic E, FAI and neutral winds further, simultaneous observations of $\mathrm{Na}$ concentration, FAI echoes, sporadic E, neutral winds are being planned. In this connection, an ionosonde has recently been installed at Gadanki, which would provide vital information on the sporadic E. The MST radar, which is being upgraded to an active phased array system, would also be capable of providing neutral winds in the MLT region through the measurements of low altitude FAI and meteor echoes. These observations are expected to throw more light to develop much deeper understanding on the complex processes of the MLT region.

Acknowledgements. The support of the NARL technical staff in conducting observations presented here is gratefully acknowledged.

Topical Editor C. Jacobi thanks two anonymous referees for their help in evaluating this paper.

\section{References}

Bhavani Kumar, Y., Narayana Rao, D., Sundara Murthy, M., and Krishnaiah, M.: Resonance lidar system for mesospheric sodium measurements, Opt. Eng., 46(8), 1, doi:10.1117/1.2767271, 2007.

Bowman, M. R., Gibson, A. J., and Sandford, M. C. W.: Atmospheric sodium measured by a tuned laser radar, Nature, 221, 456-457, 1969.

Chimonas, G. and Axford, W. I.: Vertical movement of temperate zone sporadic E layer, J. Geophys. Res., 73, 111-117, 1968.
Chimonas, G.: Enhancement of sporadic E by horizontal transport within the layer, J. Geophys. Res., 76, 4578-4586, 1971.

Clemesha, B. R.: Sporadic neutral metal layers in the mesosphere and lower thermosphere, J. Atmos. Terr. Phys., 57, 725-736, 1995.

Clemesha, B. R. Batista, P. P., and Simonich, D. M.: Simultaneous measurements of meteor winds and sporadic sodium layers in the 80-110 km region, Adv. Space Res., 27, 1679-1684, 2001.

Deepa, V., Ramkumar, G., Antonita, M., Kumar, K. K., and Sasi, M. N.: Vertical propagation characteristics and seasonal variability of tidal wind oscillations in the MLT region over Trivandrum $\left(8.5^{\circ} \mathrm{N}, 77^{\circ} \mathrm{E}\right)$ : first results from SKiYMET Meteor Radar, Ann. Geophys., 24, 2877-2889, 2006, http://www.ann-geophys.net/24/2877/2006/.

Friedman, J. S., Gonzalez, S. A., Tepley, C. A., Zhou, Q., Sulzer, M. P., Collins, S. C., and Grime, B. W.: Simultaneous atomic and ion layer enhancements observed in the mesopause region over Arecibo during the Coqui II sounding rocket campaign, Geophys. Res. Lett., 27, 449-452, 2000.

Gardner, C. S., Kane, T. J., Sneft, D. C., Qian, J., and Papen, G. C.: Simultaneous observations of sporadic $\mathrm{E}, \mathrm{Na}, \mathrm{Fe}$, and $\mathrm{Ca}+$ layers at Urbana, Illinois: three case studies, J. Geophys. Res., 98, 16868-16873, 1993.

Granier, C., Jegou, J. P., and Megie, G.: Iron atoms and metallic species in the Earth's upper atmosphere, Geophys. Res. Lett., 16, 243-246, 1989.

Haldoupis, C. and Pancheva, D.: Planetary waves and midlatitude sporadic E layers: Strong experimental evidence for a close relationship, J. Geophys. Res., 107(A6), 1078, doi:10.1029/2001JA000212, 2002.

Haldoupis, C., Schlegel, K., and Farley, D. T.: An explanation for type 1 radar echoes from the midlatitude E-region ionosphere, Geophys. Res. Lett., 23, 97-100, 1996.

Haldoupis, C., Meek, C., Christakis, N., Pancheva, D., Bourdillon, A.: Ionogram height-time-intensity observations of descending sporadic $E$ layers at mid-latitude, J. Atmos. Solar-Terr. Phys., 68, 539-557, 2006.

Hocking, W. K., Fuller, B., and Vandepeer, B.: Real time determination of meteor-related parameters utilizing modern digital technology, J. Atmos. Sol. Terr. Phys., 63, 155-169, 2001.

Kane, T. J., Gardner, C. S., Zhou, Q., Mathews, J. D., and Tepley, C. A.: Lidar, radar and airglow observations of a prominent sporadic $\mathrm{Na}$ / sporadic E layer event at Arecibo during AIDA - 89, J. Atmos. Terr. Phys., 55, 499-511, 1993.

Kane, T., Grime, B., Franke, S., Kudeki, E., Urbina, J., Kelley, M., and Collins, S.: Joint observations of sodium enhancements and field aligned ionospheric irregularities, Geophys. Res. Lett., 28, 1375-1378, 2001.

Mathews, J. D. and Bekeny, F. S.: Upper Atmosphere Tides and the Vertical Motion of Ionospheric Sporadic Layers at Arecibo, J. Geophys. Res., 84(A6), 2743-2750, 1979.

Mathews, J. D.: Sporadic-E: current views and recent progress, J. Atmos. Terr. Phys., 60, 413-435, 1998.

Pancheva, D., Haldoupis, C., Meek, C. E., Manson, A. H., and Mitchell, N. J.: Evidence of a role for modulated atmospheric tides in the dependence of sporadic E layers on planetary waves, J. Geophys. Res., 108(A5), 1176, doi:10.1029/2002JA009788, 2003.

Patra, A. K., Yokoyama, T., Yamamoto, M., Nakamura, T., 
Tsuda, T., and Fukao, S.: Lower E region field-aligned irregularities studied using the Equatorial Atmosphere Radar and meteor radar in Indonesia, J. Geophys. Res., 112, A01301, doi:10.1029/2006JA011825, 2007.

Patra, A. K., Venkateswara Rao, N., and Choudhary, R. K.: Daytime low-altitude quasi-periodic echoes at Gadanki: Understanding of their generation mechanism in the light of their Doppler characteristics, Geophys. Res. Lett., 36, L05107, doi:10.1029/2008GL036670, 2009.

Patra, A. K., Sripathi, S., Rao, P. B., and Subbarao, K. S. V.: Simultaneous VHF radar backscatter and ionosonde observations of low-latitude E region, Ann. Geophys., 23, 773-779, 2005, http://www.ann-geophys.net/23/773/2005/.

Rao, P., Jain, A., Kishore, P., Balamuralidhar, P., Damle, S., and Viswanathan, G.: Indian MST radar 1. System description and sample vector wind measurements in ST mode, Radio Sci., 30(4), 1125-1138, 1995.
Richter, E. S. and Sechrist Jr. C. F.: A meteor ablation-cluster ion atmospheric sodium theory, Geophys. Res. Lett., 6, 183-186, 1979.

Urbina, J., Kudeki, E., and Franke, S. J.: $50 \mathrm{MHz}$ radar observations of mid-latitude E-region irregularities at Salinas, Puerto Rico, Geophys. Res. Lett., 27, 2853-2856, 2000.

Venkateswara Rao, N., Patra, A. K., and Rao, S. V. B.: Some new aspects of low-latitude E-region QP echoes revealed by Gadanki radar: Are they due to Kelvin-Helmholtz instability or gravity waves?, J. Geophys. Res., 113, A03309, doi:10.1029/2007JA012574, 2008.

Whitehead, J. D.: The formation of the sporadic-E layer in the temperate zones, J. Atmos. Terr. Phys., 20, 49-58, 1961.

Zhou, Q. H. and Morton, Y. T.: Incoherent scatter radar study of photochemistry in the E-region, Geophys. Res. Lett., 32, L01103, doi:10.1029/2004GL021275, 2005. 